\title{
Chungsimyeonja-eum inhibits inflammatory responses in RAW 264.7 macrophages and $\mathrm{HaCaT}$ keratinocytes
}

Hye-Sun Lim ${ }^{1,2}$, Kim Yeji ${ }^{1}$, Chang-Seob Seo ${ }^{1}$, Sae-Rom Yoo ${ }^{1}$, Seong-Eun Jin' ${ }^{1}$, Hyeun-Kyoo Shin ${ }^{1}$ and Soo-Jin Jeong 3, $^{3 *}$

\begin{abstract}
Background: Chungsimyeonja-eum (CSYJE) is an herbal prescription used in traditional Oriental medicine for treating cerebral infarction by reducing ischemic damage. However, the effects of CSYJE on inflammation have not been verified scientifically.

Methods: Anti-inflammatory effects of CSYJE was investigated to dertermine the inhibitory effects of CSYJE against inflammation using RAW 264.7 mouse macrophages and $\mathrm{HaCaT}$ human keratinocytes. To measure the effects of CSYJE on inflammatory mediators and cytokines/chemokines, we used the following methods: cell viability assay, enzyme-linked immunosorbent assay (ELISA), western blotting, immunocytochemistry. RAW 264.7 cells were pretreated with CSYJE $(250,500$, or $1000 \mu \mathrm{g} / \mathrm{mL})$ for $4 \mathrm{~h}$ and treated with lipopolysaccharide (LPS) for additional $20 \mathrm{~h}$. HaCaT cells were stimulated with tumor necrosis factor alpha (TNF-a) and interferon gamma (IFN- $\gamma$ ) (TI), and CSYJE $(125,250$, or $500 \mu \mathrm{g} / \mathrm{mL})$ for $24 \mathrm{~h}$.

Results: CSYJE suppressed the production of nitric oxide $\left(\mathrm{NO}, \mathrm{IC}_{50} 1000 \mu \mathrm{g} / \mathrm{mL}\right)$, prostaglandin $\mathrm{E}_{2}\left(\mathrm{PGE}_{2}, \mathrm{IC}_{50}=\right.$ $12.1 \mu \mathrm{g} / \mathrm{mL})$, and interleukin $(\mathrm{IL})-6\left(\mathrm{IC}_{50}=248 \mu \mathrm{g} / \mathrm{mL}\right)$ in LPS-stimulated RAW 264.7 cells. CSYJE suppressed the effects of TI on the production of thymus and activation-regulated chemokine (TARC, IC $50=330.2 \mu \mathrm{g} / \mathrm{mL}$ ), macrophage-derived chemokine (MDC/CCL22, $\mathrm{IC}_{50}=52.5 \mathrm{\mu g} / \mathrm{mL}$ ), regulated on activation, normal T-cell expressed and secreted (RANTES/CCL5, IC $50=372.9 \mu \mathrm{g} / \mathrm{mL})$, and IL-8 $\left(I C_{50}=345.1 \mu \mathrm{g} / \mathrm{mL}\right)$ in HaCaT cells. CSYJE inhibited TIstimulated STAT1 phosphorylation in a dose-dependent manner and nuclear translocation at $500 \mu \mathrm{g} / \mathrm{mL}$ in HaCaT cells.
\end{abstract}

Conclusion: Our results suggest a possible therapeutic application of CSYJE for treating inflammatory diseases.

Keywords: Chungsimyeonja-eum, Inflammation, Cytokine, Chemokine, Macrophage, Keratinocyte

\section{Backgrounds}

Inflammation constitutes multiple processes, characterized by the infiltration of inflammatory cells, such as Th2-type cells, eosinophils, mast cells, and macrophages. Of these activated cells, macrophages play a central role in managing many different pathological immune phenomena such as the over-production of inflammatory mediators. Various mediators, such as nitric oxidase,

\footnotetext{
* Correspondence: sjijeong@kiom.re.kr

${ }^{3}$ Korean Medicine Convergence Research Division, Korea Institute of Oriental Medicine, Daejeon 34054, Republic of Korea

${ }^{4}$ Korean Medicine Life Science, University of Science \& Technology, 217

Gajeong-ro Yuseong-gu, Daejeon 34113, Republic of Korea

Full list of author information is available at the end of the article
}

prostaglandins, and inflammatory cytokines such as interleukin (IL)-6, IL-1 $\beta$ and tumor necrosis factor (TNF)- $\alpha$, and others induced by macrophages have important roles in inflammatory diseases [1-3].

Migration of inflammatory cells is regulated by chemokines. These are small proteins released from various cell types, which regulate the traffic of immune cells to site of inflammation or infection. Various inflammatory cytokines stimulate the expression of inflammatory chemokines $[4,5]$. Among them, thymus and activation-regulated chemokine (TARC/CCL17), macrophage-derived chemokine (MDC/CCL22), and regulated on activation, normal T-cell expressed and secreted (RANTES/CCL5) are typical 
inflammatory chemokines and ligands for $\mathrm{CC}$ chemokine receptor 4 (CCR4), which is predominantly expressed on keratinocytes, Th2 lymphocytes, and basophils [6, 7]. In addition, IL-8 is another inflammatory mediator involved in allergic responses that is closely associated with the severity of chronic inflammation [8].

Extracellular binding of cytokines induces activation of the intracellular Janus kinase (JAK) that phosphorylates a specific tyrosine residue in signal transducer and activator of transcription (STAT) proteins [9], which are involved in the development and function of the immune system [10]. There are seven mammalian STAT family members that have been identified: STAT1, STAT2, STAT3, STAT4, STAT5 (STAT5A and STAT5B) and STAT6. In particular, STAT1 is a crucial molecule for the interferon (IFN)/cytokine-signaling pathways [11]. Thus, IFN- $\gamma$ stimulates JAK phosphorylation, which in turn induces STAT1 phosphorylation [12]. These events eventually increase the production of chemokines including TARC, MDC, and RANTES [13, 14].

The traditional herbal formula Chungsimyeonja-eum (CSYJE) comprises nine medicinal herbs and has traditionally been used in the treatment of heart and brain diseases in Oriental medicine. Previous research reported that the water extract of CSYJE has cytoprotective effect against glutamate-induced C6 glial cell death [15]. Other studies showed that CSYJE protects against ischemic stroke and has anti-stress activity $[16,17]$. However, there has been no investigation focusing on the inflammatory effects of CSYJE. Therefore, we investigated the effects and action mechanisms of CSYJE on the inflammatory mediators in RAW 264.7 macrophages and $\mathrm{HaCaT}$ keratinocytes.

\section{Methods}

\section{Preparation of CSYJE water extract}

The 9 crude herbal medicines forming CSYJE were purchased from Kwangmyungdang Medicinal Herbs (Ulsan, Korea). The origin of 9 herbal medicines was confirmed taxonomically by Professor Je-Hyun Lee, Dongguk University, Gyeongju, Republic of Korea. A voucher specimen (2012-KE43-1 KE43-9) has been deposited at K-herb Research Center, Korea Institute of Oriental Medicine. For preparation of CSYJE water decoction, each herbal medicine was mixed as Table 1 (total weight $=$ $5.0 \mathrm{~kg}$, about 156.9 times of composition of single dose) and extracted in distilled water at $100{ }^{\circ} \mathrm{C}$ for $2 \mathrm{~h}$ under pressure (98 $\mathrm{kPa}$ ) using an electric extractor (COSMOS660; Kyungseo Machine Co., Incheon, Korea). The extract solution was filtrated using a standard sieve (No. 270, $53 \mu \mathrm{m}$; Chung Gye Sang Gong Sa, Seoul, Korea) and freeze-dried to give a powder sample. The yield of CSYJE extract was $13.0 \%$ (651.4 g).

\section{High-performance liquid chromatography (HPLC) analysis of CSYJE}

Quantitative analysis of the CSYJE sample was performed using a Shimadzu LC-20A Prominence HPLC system (Shimadzu Co., Kyoto, Japan) consisting of a solvent delivery unit, an on-line degasser, a column oven, an autosampler, and a photo diode array (PDA) detector. The data were acquired and processed by LabSolution software (Version 1.24 SP1). A SunFire $\mathrm{C}_{18}$ column $(250 \times 4.6 \mathrm{~mm}$; particle size $5 \mu \mathrm{m}$, Waters, Milford, MA, USA), which was maintained at $40{ }^{\circ} \mathrm{C}$, was used as the stationary phase and the mobile phases were consisted of $0.1 \%(\mathrm{v} / \mathrm{v})$ formic acid in water (A) and $0.1 \%(\mathrm{v} / \mathrm{v})$ formic acid in acetonitrile (B). The elution conditions were as follows: 10-60\% B for $0-30 \mathrm{~min}, 60-100 \% \mathrm{~B}$ for $30-40 \mathrm{~min}, 100 \% \mathrm{~B}$ for $40-45 \mathrm{~min}$, and $100-10 \% \mathrm{~B}$ for $45-50 \mathrm{~min}$. The flow-rate was $1.0 \mathrm{~mL} / \mathrm{min}$ and injection volume was $10 \mu \mathrm{L}$. For HPLC analysis of CSYJE, lyophilized $200 \mathrm{mg}$ of CSYJE extract was dissolved in $20 \mathrm{~mL}$ of distilled water and then the solution was diluted to 10 -fold for quantitative analysis of baicalin and wogonoside. Each solution was filtered through a SmartPor GHP $0.2 \mu \mathrm{m}$ syringe filter (Woongki Science, Seoul, Korea) before HPLC injection.

Table 1 Herbal composition of a single dose of CSYJE

\begin{tabular}{llll}
\hline Latin name & Scientific name & Amount (g) & Origin \\
\hline Nelumbinis Semen & Nelumbo nucifera Gaerhner & 7.500 & China \\
Poria Sclerotium & Poria cocos Wolf & 3.750 & Pyeongchang, Korea \\
Ginseng Radix & Panax ginseng C. A. Meyer & 3.750 & Yeongju, Korea \\
Astragali Radix & Astragalus membranaceus Bunge & 3.750 & Jecheon, Korea \\
Scutellariae Radix & Scutellaria baicalensis Georgi & 2.625 & Gurye, Korea \\
Plantaginis Semen & Plantago asiatica L. & 2.625 & China \\
Liriope Tuber & Liriope platyphylla Wang et Tang & Miryang, Korea \\
Lycii Radicis Cortex & Lycium chinense Miller & 2.625 & China \\
Glycyrrhizae Radix et Rhizoma & Glycyrrhiza uralensis Fischer & 2.625 & China \\
Total & & 2.625 & 1.875 \\
\hline
\end{tabular}




\section{Cell cultures}

Murine macrophage RAW 264.7 and human keratinocyte $\mathrm{HaCaT}$ were obtained from the American Type Culture Collection (Rockville, MD) and CLS Cell Lines Service GmbH (Eppelheim, Baden-Württemberg, Germany), respectively. The cells were cultured in Dulbecco's modified Eagle's medium (Gibco Inc., Grand Island, NY) supplemented with $5.5 \%$ (for RAW 264.7) or $10 \%$ (for $\mathrm{HaCaT}$ ) heat-inactivated fetal bovine serum (Gibco Inc.), penicillin $(100 \mathrm{U} / \mathrm{mL})$, and streptomycin $(100 \mu \mathrm{g} / \mathrm{mL})$ in a $5 \% \mathrm{CO}_{2}$ incubator at $37^{\circ} \mathrm{C}$.

\section{Cytotoxicity assay}

Cell viability was assessed using a Cell Counting Kit-8 assay (CCK-8 from Dojindo, Kumamoto, Japan) according to the manufacturer's instructions. RAW 264.7 cells $\left(3 \times 10^{3}\right.$ cells/well $)$ and $\mathrm{HaCaT}$ cells $(1 \times$ $10^{3}$ cells/well) were incubated in 96-well plates with various concentrations of the CSYJE for $24 \mathrm{~h}$. The CCK-8 reagent was added to each well, followed by incubation for an additional $4 \mathrm{~h}$, and the absorbance was measured at $450 \mathrm{~nm}$ using a Benchmark plus microplate reader (Bio-Rad Laboratories, Hercules, CA). The percentage of viable cells was calculated using the following equation: cell viability $(\%)=($ mean absorbance in test well/mean absorbance in control well) $\times$ 100.

\section{Measurement of nitric oxide (NO), prostaglandin $E_{2}$ $\left(\mathrm{PGE}_{2}\right)$, and IL-6 production}

RAW 264.7 cells were plated at a density of $2.5 \times 10^{5}$ cells/well in 48-well plates and incubated overnight. Cells were pretreated with various concentrations of CSYJE for $4 \mathrm{~h}$ and then treated with LPS $(1 \mu \mathrm{g} / \mathrm{mL})$ for an additional $20 \mathrm{~h}$. The supernatants were collected and analyzed for the levels of NO (Griess Reagent System; Promega Corp., Madison, WI), and $\mathrm{PGE}_{2}$ and IL-6 using enzyme-linked immunosorbent assay (ELISA) kits (Cayman Chemical Co., Ann Arbor, MI for $\mathrm{PGE}_{2}$, and R\&D Systems, Minneapolis, MN) according to the manufacturers' protocols.

\section{Measurement of chemokine production}

$\mathrm{HaCaT}$ cells $\left(1 \times 10^{6}\right.$ cells/well $)$ were cultured in 6well plates. After reaching confluency, the cells were washed and treated with CSYJE in $1 \mathrm{~mL}$ of serumfree medium containing tumor necrosis factor- $\alpha$ (TNF- $\alpha$ ) and interferon- $\gamma$ (IFN- $\gamma$ ) (TI, each $10 \mathrm{ng} / \mathrm{mL}$; R\&D Systems Inc., Minneapolis, MN, USA) for $24 \mathrm{~h}$. The production of TARC, MDC, RANTES, and IL-8 was determined using commercial ELISA kits (R\&D Systems Inc.).

\section{Western blotting}

$\mathrm{HaCaT}$ cells were treated with a nontoxic concentration of CSYJE for $1 \mathrm{~h}$, and then incubated in the presence of TI for $30 \mathrm{~min}$. The cells were collected by centrifugation, washed twice with PBS, and suspended in an extraction lysis buffer (Sigma-Aldrich, St. Louis, MO) containing protease inhibitors. The protein concentration was determined using a protein assay reagent (Bio-Rad Laboratories, Hercules, CA) according to the manufacturer's instructions. Equal amounts of total protein $(30 \mu \mathrm{g})$ were resolved by 10 $\%$ sodium dodecyl sulfate-polyacrylamide gel electrophoresis (SDS-PAGE) and transferred to a nitrocellulose membrane. The membrane was incubated with blocking solution [5 \% skim milk in Tris-buffered saline containing Tween 20 (TBST)], followed by an overnight incubation at $4{ }^{\circ} \mathrm{C}$ with the appropriate primary antibody. The following primary antibodies and dilution were used: anti- $\beta$-actin (1:1000 dilution; Cell Signaling, Danvers, MA), anti-STAT1, and antiphospho-STAT1 (1:1000 dilution; Abcam, Cambridge, UK). The membranes were washed three times with TBST, and then incubated with a 1:3000 dilution of a horseradish peroxidase (HRP)-conjugated secondary antibody (Jackson ImmunoResearch, West Grove, PA) for $1 \mathrm{~h}$ at room temperature. The membranes were again washed three times with TBST, and then developed using an enhanced chemiluminescence (ECL) kit (Thermo scientific, Rockford, IL). Image capture was performed using Chemi-Doc (Bio-Rad).

\section{Immunofluorescence staining}

$\mathrm{HaCaT}$ cells were seeded onto glass coverslips and incubated with $\mathrm{TI}$ in the absence or presence of CSYJE $(500 \mu \mathrm{g} / \mathrm{mL})$ for $30 \mathrm{~min}$. The cells were fixed in $4 \%$ paraformaldehyde and $100 \%$ acetone, blocked in $0.5 \%$ bovine serum albumin, and incubated with anti-STAT1 antibody (Cell Signaling, Danvers, MA) for $1 \mathrm{~h}$ at room temperature. Then, fluorescein isothiocyanate (FITC)-conjugated anti-rabbit immunoglobulin G (IgG) antibody (Invitrogen, Carlsbad, CA) was used as a secondary antibody. The immunostained cells were mounted with medium containing 4'6-diamidino-2-phenylindole (DAPI) and visualized using an Olympus FLUOVIEW FV10i confocal microscope (Tokyo, Japan).

\section{Statistical analysis}

The data are expressed as the mean \pm SEM. Data were analyzed using one-way analysis of variance and Dunnett's multiple comparisons test. Results with a $P$ value $<0.05$ were considered to be statistically significant. 


\section{Results}

Identification and quantification of the marker components in CSYJE

Calibration curves of the five marker components showed good linearity with correlation coefficient $\left(r^{2}\right) \geq$ 0.9998 in the different concentration ranges. Using optimized chromatography conditions, Three-dimensional chromatogram was obtained using HPLC-PDA detector and the five marker compounds were eluted within 35 min (Fig. 1). The amounts of the five marker compounds, liquiritin apioside, liquiritin, baicalin, wogonoside, and glycyrrhizin, were $1.43 \pm 0.02,2.00 \pm$ $0.03,22.52 \pm 0.36,7.11 \pm 0.02$, and $2.49 \pm 0.02 \mathrm{mg} / \mathrm{g}$, respectively.

\section{Effects of CSYJE on cell viability of RAW 264.7 mouse} macrophages and $\mathrm{HaCaT}$ human keratinocytes

To examine the effect of CSYJE on cell viability, RAW 264.7 cells and $\mathrm{HaCaT}$ cells were treated with various concentration ranging from 250 to $1000 \mu \mathrm{g} / \mathrm{mL}$ and 125 to $500 \mu \mathrm{g} / \mathrm{mL}$ of CSYJE for $24 \mathrm{~h}$, respectively. As shown in Fig. 2, the survival of RAW 264.7 cells and HaCaT cells were not affected by exposure to concentration of CSYJE compared to that of the controls. Therefore, nontoxic concentrations $(250,500$, or $1000 \mu \mathrm{g} / \mathrm{mL}$ in
RAW 264.7 cells; 125, 250, or $500 \mu \mathrm{g} / \mathrm{mL}$ in $\mathrm{HaCaT}$ cells) of CSYJE were used for the subsequent experiments.

\section{CSYJE inhibits production of pro-inflammatory mediators} in lipopolysaccharide (LPS)-stimulated RAW 264.7 cells

To determine the effects of CSYJE on $\mathrm{NO}$ and $\mathrm{PGE}_{2}$ production following LPS stimulation, RAW 264.7 cells were pretreated with various concentrations of CSYJE $(0,250,500$, or $1000 \mu \mathrm{g} / \mathrm{mL})$ for $4 \mathrm{~h}$ and then stimulated with LPS $(1 \mu \mathrm{g} / \mathrm{mL})$ for an additional $20 \mathrm{~h}$. CSYJE suppressed LPS-stimulated NO production in a dosedependent manner (Fig. 3a). LPS significantly stimulated NO production by RAW 264.7 cells $(14.42 \pm 0.24 \mu \mathrm{M})$. By contrast, CSYJE significantly decreased NO production to $9.67 \pm 0.09 \mu \mathrm{M}(P<0.01)$ at $500 \mu \mathrm{g} / \mathrm{mL}$ and to $5.76 \pm 0.15 \mu \mathrm{M}(P<0.01)$ at a dose of $1000 \mu \mathrm{g} / \mathrm{mL} \mathrm{PGE}_{2}$ production was higher in LPS-stimulated RAW 264.7 cells than in untreated control cells, whereas CSYJE dose-dependently inhibited $\mathrm{PGE}_{2}$ production by LPS stimulation (Fig. 3b). Furthermore, LPS treatment dramatically increased IL-6 level up to $123.96 \mathrm{ng} / \mathrm{mL}$ compared with untreated control. In contrast, CSYJE significantly inhibited IL-6 production by 54.82 , 55.31, and $66.89 \%$ at 250,500 , and $1000 \mu \mathrm{g} / \mathrm{mL}$, respectively (Fig. 3c).

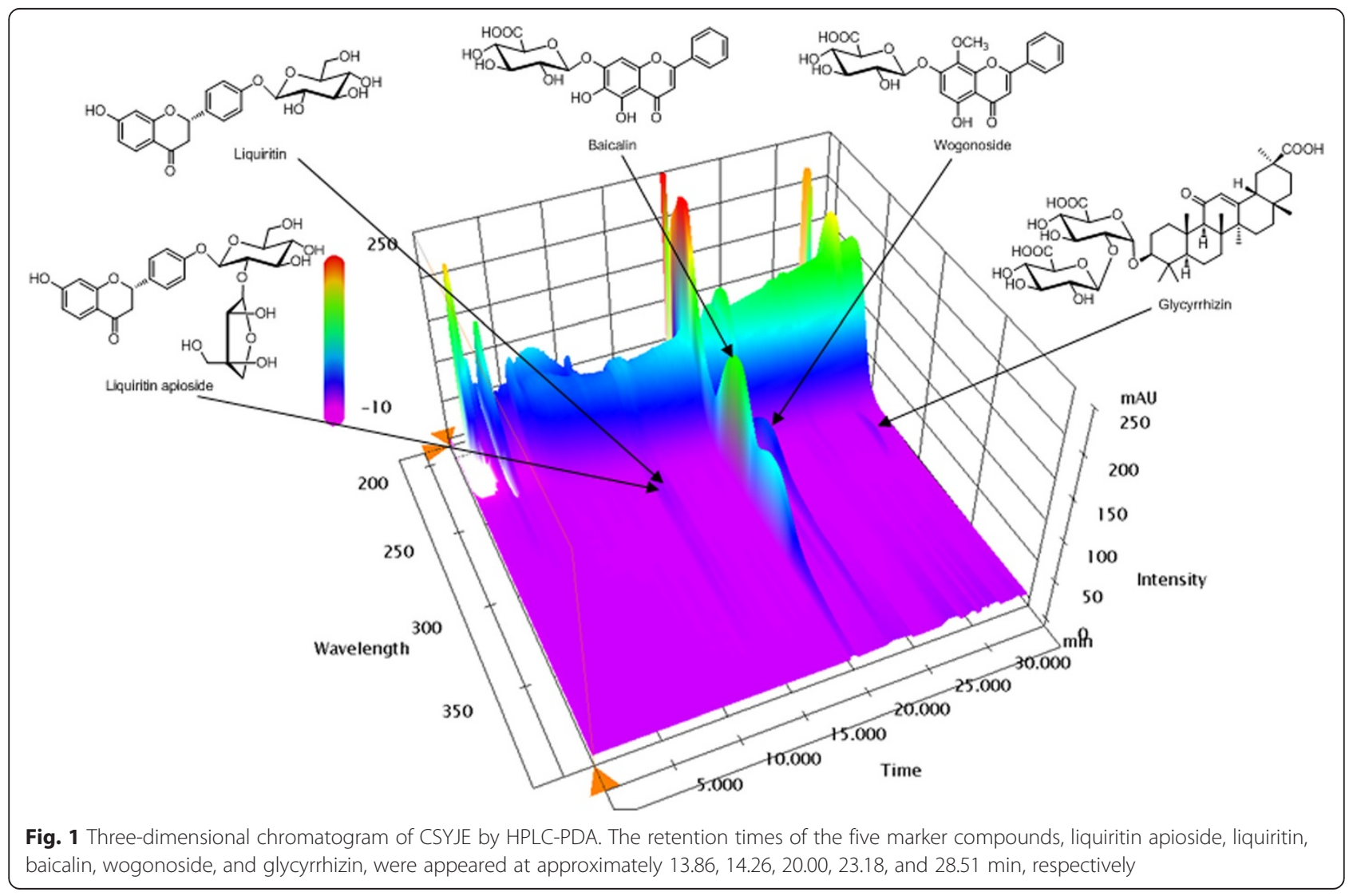



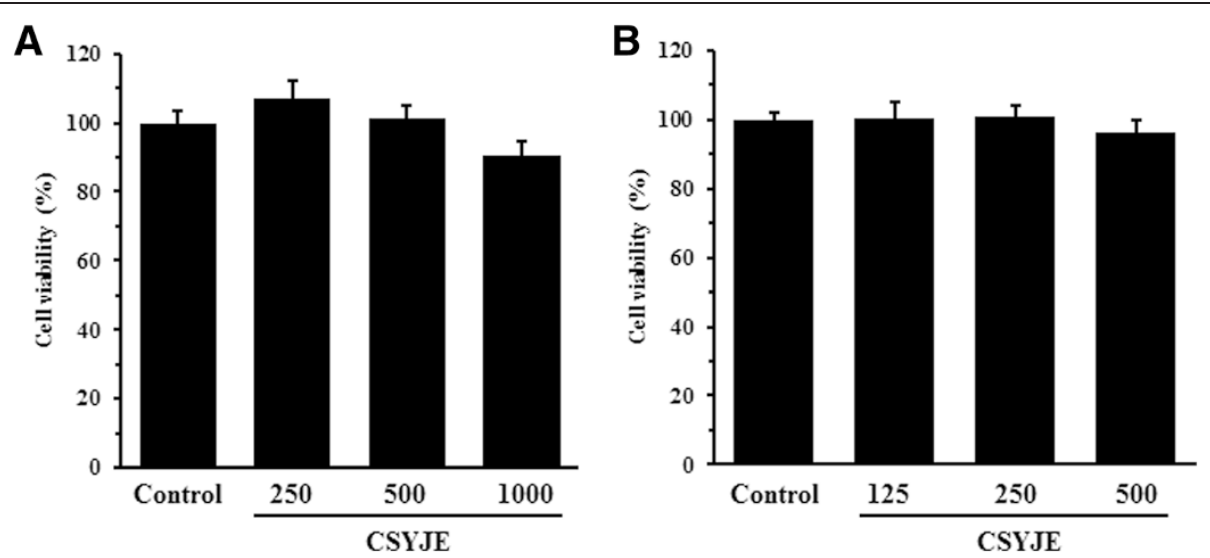

Fig. 2 Cytotoxicity of CSYJE against RAW 264.7 cells or HaCaT cells. RAW 264.7 (a) or HaCaT (b) cells were seeded onto 96-well plates and treated with various concentrations of CSYJE for $24 \mathrm{~h}$. Cell viability (\%) was assessed using a CCK-8 assay. The values are expressed as the mean \pm SEM of three independent experiments

\section{CSYJE inhibits chemokine production in TNF- $a$ and} IFN- $\gamma$-stimulated HaCaT cells

The effects of CSYJE on TARC, MDC, RANTES, and IL-8 production levels were assessed in TI-stimulated $\mathrm{HaCaT}$ cells. As shown in Fig. 4a, HaCaT cells treated with TI increased the TARC level $(10.78 \pm 1.21 \mathrm{ng} / \mathrm{mL}$,
$P<0.01)$ compared with the vehicle-treated cells $(0.65 \pm$ $0.18 \mathrm{ng} / \mathrm{mL}$ ). By contrast, CSYJE suppressed TI-stimulated TARC production in a dose-dependent manner. The levels were reduced by $6.44 \pm 0.35 \mathrm{ng} / \mathrm{mL}(P<0.01)$ and $1.88 \pm 0.45 \mathrm{ng} / \mathrm{mL}(P<0.01)$ using 250 and $500 \mu \mathrm{g} /$ $\mathrm{mL}$, respectively. MDC production in TI-treated cells

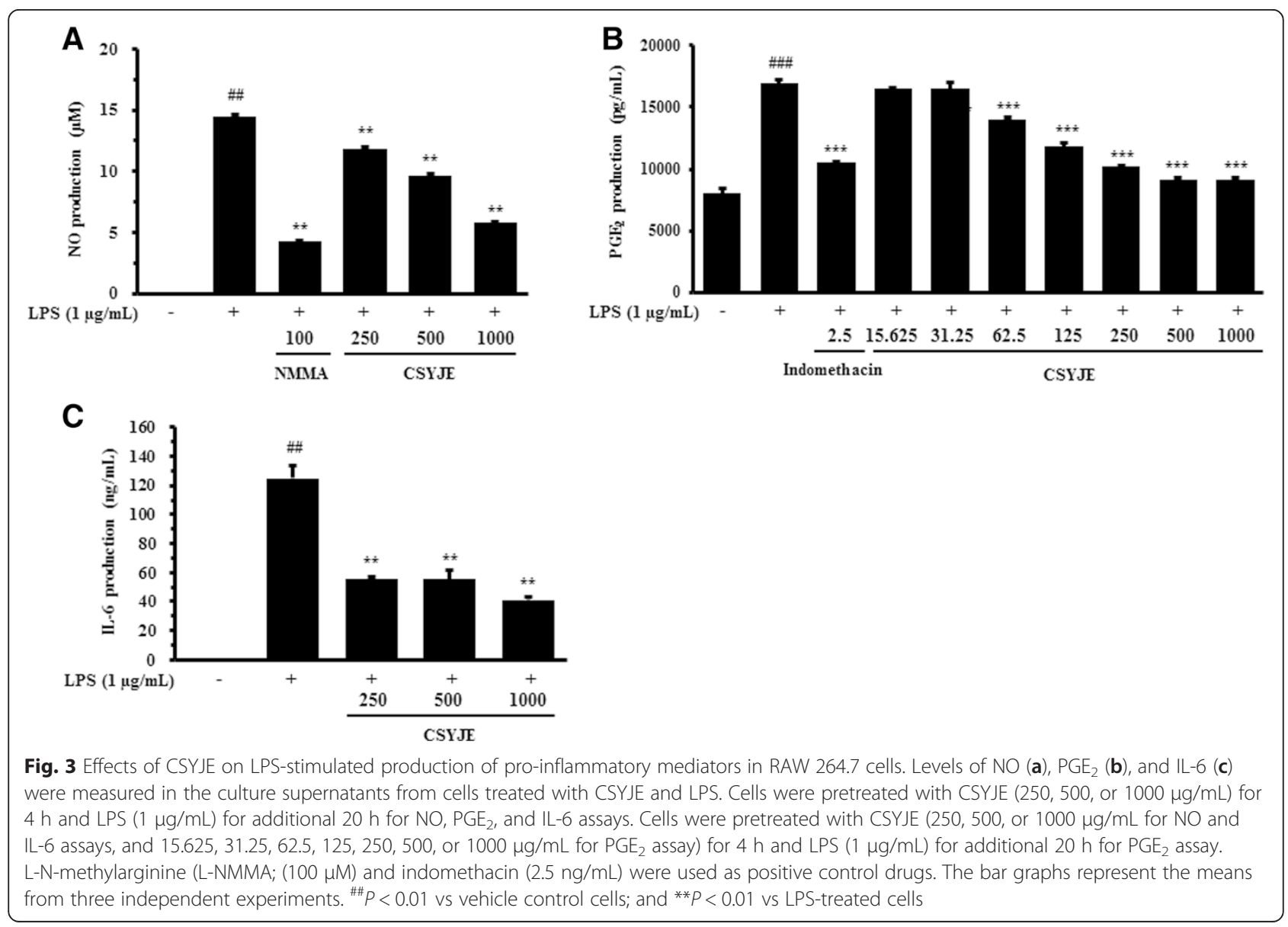




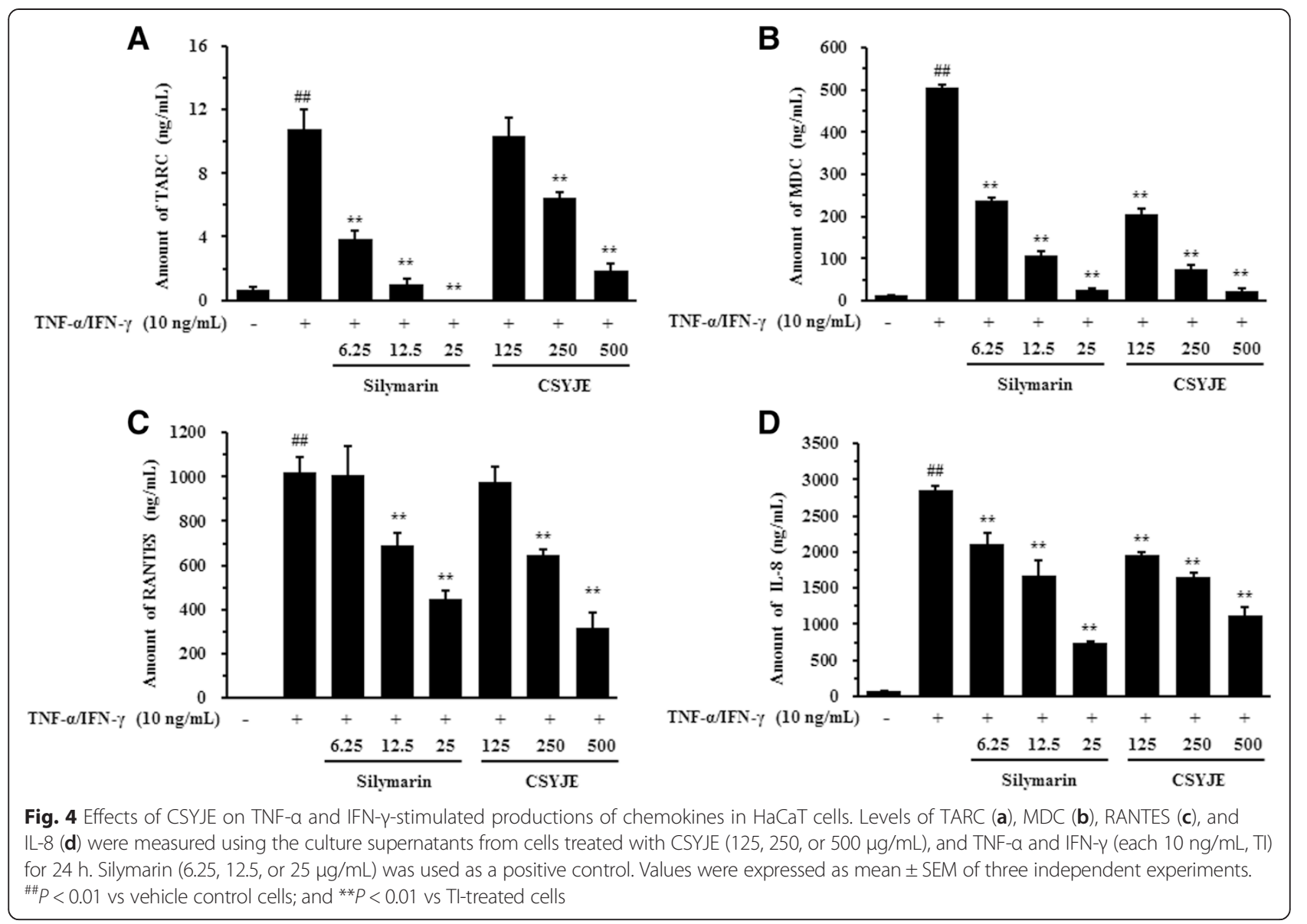

was also increased $(506.70 \pm 7.27 \mathrm{ng} / \mathrm{mL}, P<0.01)$ compared with vehicle-treated cells, but the levels were reduced significantly after treatment with CSYJE treatment $(205.25 \pm 16.80 \mathrm{ng} / \mathrm{mL}$ at $125 \mu \mathrm{g} / \mathrm{mL}, P<0.01 ; 74.15 \pm$ $11.59 \mathrm{ng} / \mathrm{mL}$ at $250 \mu \mathrm{g} / \mathrm{mL}, P<0.01$; and $24.34 \pm 4.69 \mathrm{ng} /$ $\mathrm{mL}$ at $500 \mu \mathrm{g} / \mathrm{mL}, P<0.01$ ) (Fig. $4 \mathrm{~b}$ ). TI-treated cells produced significantly more RANTES $(1019.80 \pm 66.97 \mathrm{ng} /$ $\mathrm{mL}, P<0.01)$ compared with the vehicle-treated cells. The TI-induced increase in RANTES production was significantly inhibited by CSYJE $(644.18 \pm 29.79 \mathrm{ng} / \mathrm{mL}$ at $250 \mu \mathrm{g} / \mathrm{mL}, P<0.01$; and $319.94 \pm 68.15 \mathrm{ng} / \mathrm{mL}$ at $500 \mu \mathrm{g} /$ $\mathrm{mL}, P<0.01$ ) (Fig. 4c). In addition, the level of IL-8 $(2848.74 \pm 98.83 \mathrm{ng} / \mathrm{mL}, P<0.01)$ was also significantly reduced by CSYJE in a dose-dependent manner (1648.33 \pm $56.81 \mathrm{ng} / \mathrm{mL}$ at $250 \mu \mathrm{g} / \mathrm{mL}, P<0.01$; and $1126.23 \pm$ $38.02 \mathrm{ng} / \mathrm{mL}$ at $500 \mu \mathrm{g} / \mathrm{mL}, P<0.01$ ) (Fig. $4 \mathrm{~d}$ ). The inhibitory effects of CSYJE were similar to those of silymarin, which was used as a positive control.

\section{CSYJE inhibits STAT1 phosphorylation in TNF- $a$ and IFN- $\gamma$-stimulated $\mathrm{HaCaT}$ cells}

TI-stimulated $\mathrm{HaCaT}$ cells showed markedly increased STAT1 phosphorylation compared with non-stimulated $\mathrm{HaCaT}$ cells. Treatment with silymarin reduced the level of STAT1 phosphorylation compared with TI stimulation alone. Treatment with CSYJE showed a dramatic reduction in STAT1 phosphorylation in a dose-dependent manner (Fig. 5a). Consistent with the results of western blotting, immunofluorescence staining revealed that CSYJE inhibited the TI-induced nuclear localization of STAT1 in HaCaT cells (Fig. 5b).

\section{Discussion}

CSYJE, a traditional herbal fomula, is composed of 9 medicinal herbs such as Nelumbinis Semen, Poria Sclerotium, Ginseng Radix, Astragali Radix, Scutellariae Radix, Plantaginis Semen, Liriope Tuber, Lycii Radicis Cortex, and Glycyrrhizae Radix et Rhizoma and has been used to treat neuropsychiatric disease, stroke, renal tuberculosis, stomatitis, pyelitis, and cystitis in Korea [18]. The major components of the 9 herbal medicines are known as follows: flavonoids (e.g. isoquercitrin and quercetin-3-O-glucuronide) from Nelumbinis Semen [14], triterpenoids (e.g. pachymic acid and dehydropachymic acid) from Poria Sclerotium [19, 20], triterpenoids (e.g. ginsenoside Rb1 and Rb1) from Ginseng Radix [21], flavonoids (e.g. formononetin and calycosin-7-O-glucoside) from Astragali Radix [22], flavonoids (e.g. baicalin 


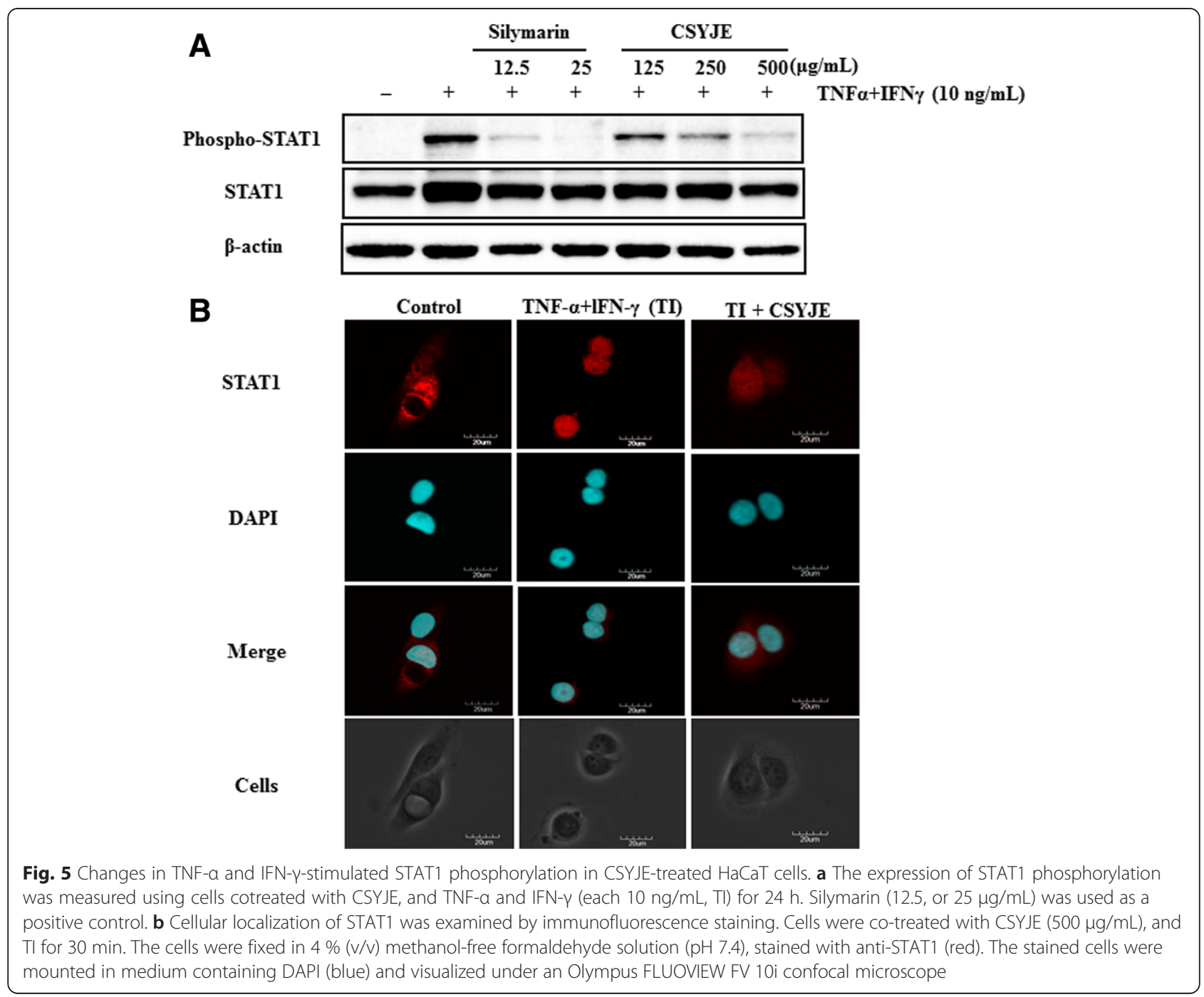

and wogonoside) from Scutellariae Radix [23], iridoids (e.g. genoiposide and genipsidic acid) form Plantaginis Semen [24, 25], steroid saponins (e.g. spicatoside A and B) form Liriope Tuber [26], phenylpropanoid (chlorogenic acid) and flavonoid (e.g. rutin) form Liriope Tuber [27], and triterpene saponin (e.g. glycyrrhizin) and flavonoids (e.g. liquiritin and liquiritigenin), from Glycyrrhizae Radix et Rhizoma [28]. Among those constituents, we tried to analyze 19 compounds, such as hyperoside, isoquercitrin, pachymic acid, ginsenoside Rb1, ginsenoside Rg1, formononetin, baicalin, baicalenin, wogonoside, wogonin, geniposide, geniposidic acid, spicatoside A, chlorogenic acid, rutin, liquiritigenin, liquiritin, liquiritin apioside, and glycyrrhizin using optimized HPLC-PDA method in CSYJE sample. Consequently, the main components of Scutellariae Radix Glycyrrhizae Radix et Rhizoma, liquiritin apioside, liquiritin, baicalin, wogonoside, and glycyrrhizin were detected. However, other components were not detected in this sample. Finally, baicalin $(22.52 \pm 0.36 \mathrm{mg} / \mathrm{g})$, marker compound of Scutellariae Radix, was detected as the major compound in CSYJE extract.

In the present study, we found that CSYJE inhibited the actions of various inflammatory mediators. CSYJE inhibited production of the pro-inflammatory mediators $\mathrm{NO}$ and $\mathrm{PGE}_{2}$, and cytokine IL-6 in LPS-stimulated macrophages. CSYJE also inhibited the production of the chemokines TARC, MDC, RANTES, and IL-8, and suppressed STAT1 activation in TI-treated keratinocytes. Macrophages, as innate immune cells, initiate inflammation and the immune response [29]. When challenged with LPS, macrophages are activated and release various pro-inflammatory factors, excessive release of which can result in extensive tissue damage and pathological changes. NO, an important cellular signaling molecule and pro-inflammatory mediator produced by inducible nitric oxide synthase (iNOS), plays a key role in the pathogenesis of inflammation caused by its overproduction in abnormal situations [30]. $\mathrm{PGE}_{2}$ is another important 
pro-inflammatory factor regulated by cyclooxygenase- 2 (COX-2). Its expression is elevated in LPS-stimulated macrophages, and is associated with many chronic inflammatory diseases including cardiovascular diseases, arthritis, inflammatory bowel disease, angiogenesis, and chronic gastric ulcers [31-33]. Macrophages also release proinflammatory cytokines including IL-1 $\beta$, IL- 6 , and TNF- $\alpha$, which are used to evaluate potential anti-inflammatory properties of agents against LPS-induced macrophage activation [34]. In the present study, CSYJE significantly inhibited the concentrations of $\mathrm{NO}$ and $\mathrm{PGE}_{2}$ in the supernatant in LPS-stimulated RAW 264.7 cells. Thus, CSYJE might reduce inflammatory responses by inhibiting IL-6 secretion.

Keratinocytes produce various chemokines, which are involved in the development of inflammatory diseases. TARC and MDC are produced by dendritic cells, endothelial cell and keratinocytes which bind and attract CCR4+ Th2 cells into inflammatory tissues [7]. Several studies have reported that there are high levels of TARC and MDC in the serum of patients with atopic dermatitis [35]. The severity of atopic dermatitis was significantly correlated with these chemokine levels [36]. RANTES is overexpressed in the keratinocytes of such patients. In addition, RANTES has a significant role in the inflammatory process of psoriasis. Here, we found that CSYJE inhibited TARC, MDC, RANTES, and IL-8 production in TI-stimulated $\mathrm{HaCaT}$ keratinocytes.

STAT1 is also a pivotal regulator of IFN- $\gamma$-induced immune responses [37]. The activated STAT1 pathway can modulate the expression of numerous inflammatory mediators, including chemokines [14]. Here we demonstrated that CSYJE inhibited the TI-induced phosphorylation and nuclear translocation of STAT1 in HaCaT cells. These data suggest that CSYJE might block the induction of chemokine production including TARC, MDC, and RANTES in TI-treated keratinocytes by inhibiting STAT1 activation.

\section{Conclusions}

Our present study demonstrated that CSYJE inhibited the levels of NO, PGE 2 , and IL-6 in LPS-stimulated RAW 264.7 cells, and reduced the production of chemokines TARC, MDC, RANTES, and IL- 8 by suppressing the activation of STAT1 in TI-stimulated HaCaT cells. Further elucidation of the signaling pathways involved in the inhibition of inflammatory mediators by CSYJE is now needed to facilitate the design of therapeutic agents for inflammatory diseases.

\section{Competing interests}

The authors declare that they have no competing interests.

\section{Authors' contributions}

HSL and SJJ participated in the design of the study data analyses and manuscript preparation. YJK, CSS, SRY, and SEJ performed experiments. All authors read and approved the final manuscript.

\section{Acknowledgement}

This research was supported by a grant for "Construction of Scientific Evidence for Herbal Medicine Formulas (K14030)", from the Korea Institute of Oriental Medicine (KIOM).

\section{Author details}

'K-herb Research Center, Korea Institute of Oriental Medicine, Daejeon 34054, Republic of Korea. ${ }^{2}$ Division of Allergy and Chronic Respiratory Diseases, Center for Biomedical Sciences, Korea National Institute of Health, Chungcheongbuk-do 28159, Republic of Korea. ${ }^{3}$ Korean Medicine Convergence Research Division, Korea Institute of Oriental Medicine, Daejeon 34054, Republic of Korea. ${ }^{4}$ Korean Medicine Life Science, University of Science \& Technology, 217 Gajeong-ro Yuseong-gu, Daejeon 34113, Republic of Korea.

Received: 7 July 2015 Accepted: 7 October 2015

Published online: 16 October 2015

\section{References}

1. Coleman JW. Nitric oxide in immunity and inflammation. Int Immunopharmacol. 2001;1(8):1397-406.

2. Duffield JS. The inflammatory macrophage: a story of Jekyll and Hyde. Clin Sci (Lond). 2003;104(1):27-38.

3. Maruotti N, Cantatore FP, Crivellato E, Vacca A, Ribatti D. Macrophages in rheumatoid arthritis. Histol Histopathol. 2007;22(5):581-6.

4. Kakinuma T, Nakamura K, Wakugawa M, Mitsui $\mathrm{H}$, Tada Y, Saeki H, et al. Thymus and activation-regulated chemokine in atopic dermatitis: Serum thymus and activation-regulated chemokine level is closely related with disease activity. J Allergy Clin Immunol. 2001;107(3):535-41.

5. Pivarcsi A, Homey B. Chemokine networks in atopic dermatitis: traffic signals of disease. Curr Allergy Asthma Rep. 2005;5(4):284-90.

6. Yamashita U, Kuroda E. Regulation of macrophage-derived chemokine (MDC, CCL22) production. Crit Rev Immunol. 2002;22(2):105-14.

7. Saeki H, Tamaki K. Thymus and activation regulated chemokine (TARC)/ CCL17 and skin diseases. J Dermatol Sci. 2006;43(2):75-84.

8. Casas C, Ribet V, Alvarez-Georges S, Sibaud V, Guerrero D, Schmitt AM, et al. Modulation of Interleukin-8 and staphylococcal flora by Avene hydrotherapy in patients suffering from chronic inflammatory dermatoses. J Eur Acad Dermatol Venereol. 2011;25 Suppl 1:19-23.

9. Kwon DJ, Bae YS, Ju SM, Goh AR, Youn GS, Choi SY, et al. Casuarinin suppresses TARC/CCL17 and MDC/CCL22 production via blockade of NF-kappaB and STAT1 activation in HaCaT cells. Biochem Biophys Res Commun. 2012;417(4):1254-9.

10. Singh RK, Dai Y, Staudinger JL, Muma NA. Activation of the JAK-STAT pathway is necessary for desensitization of 5-HT2A receptor-stimulated phospholipase C signalling by olanzapine, clozapine and MDL 100907. Int J Neuropsychopharmacol. 2009;12(5):651-65.

11. Takaoka A, Taniguchi T. New aspects of IFN-alpha/beta signalling in immunity, oncogenesis and bone metabolism. Cancer Sci. 2003;94(5):405-11.

12. Tu HQ, Li XY, Tang MY, Gao JW, Xu LF, Chen ZQ, et al. Effects of tacrolimus on IFN-gamma signaling in keratinocytes: possible mechanisms by which tacrolimus affects IFN-gamma-dependent skin inflammation. Eur J Dermatol. 2011;21(1):22-31.

13. Han EH, Hwang YP, Choi JH, Yang JH, Seo JK, Chung YC, et al. Psidium guajava extract inhibits thymus and activation-regulated chemokine (TARC/ CCL17) production in human keratinocytes by inducing heme oxygenase-1 and blocking NF-kappaB and STAT1 activation. Environ Toxicol Pharmacol. 2011;32(2):136-45.

14. Hongqin T, Xinyu L, Heng G, Lanfang X, Yongfang W, Shasha S. Triptolide inhibits IFN-gamma signaling via the Jak/STAT pathway in $\mathrm{HaCaT}$ keratinocytes. Phytother Res. 2011;25(11):1678-85.

15. Ko SJ, Shin YJ, Jang WS, Ha YJ, Lee SA, Ahn MS, et al. Protective Effects of Chungsimyeonja-eum on Glutamate-induced Apoptosis in C6 Glial Cells. Kor J Orient Int Med. 2010;31:54-65.

16. Park SI, Lee WC. Effect of Chengsimyeunja-eum and Sunghyangjungi-san on streptozotocin-induced ischemic damaged diabetic rats. J Kor Orient Med. 2007;28:216-31.

17. Yoon JH, Ko IK, Shin MS, Kim CJ, Lee CY. Anti-stress and anti-nociceptive effects of the aqueous extracts of Chungsimyeonja-eum against immobilization stress and incision pain in rats. J Orient Med Physiol. 2007;21:874-83. 
18. Hur J. Donguibogam. Seoul, Korea: Namsandang; 2004. p. 507.

19. Li G, Xu ML, Lee CS, Woo MH, Chang HW, Son JK. Cytotoxicity and DNA topoisomerases inhibitory activity of constituents from the sclerotium of Poria cocos. Arch Pharm Res. 2004;27(8):829-33.

20. Hoang L, Kwon SH, Kim KA, Hur JM, Kang YH, Song KS. Chemical standardization of Poria cocos. Kor J Pharmacogn. 2005;36:177-85.

21. Shan SM, Luo JG, Huang F, Kong LY. Chemical characteristics combined with bioactivity for comprehensive evaluation of Panax ginseng C.A. Meyer in different ages and seasons based on HPLC-DAD and chemometric methods. J Pharm Biomed Anal. 2014;89:76-82.

22. Lee EJ, Yean MH, Jung HS, Kim JS, Kang SS. Phytochemical studies on Astragalus Root (2) - Flavonoids and a lignin. Nat Prod Sci. 2008;14:131-7.

23. Tong L, Wan M, Zhang L, Zhu Y, Sun H, Bi K. Simultaneous determination of baicalin, wogonoside, baicalein, wogonin, oroxylin A and chrysin of Radix scutellariae extract in rat plasma by liquid chromatography tandem mass spectrometry. J Pharm Biomed Anal. 2012;70:6-12.

24. Kim BH, Park KS, Chang IM. Elucidation of anti-inflammatory potencies of Eucommia ulmoides bark and Plantago asiatica seeds. J Med Food. 2009;12(4):764-9.

25. Oh JS, Lee JG, Jung HW, Choi JY, Choi EH, Kim DC, et al. Isolation of melanin biosynthesis inhibitory compounds from the seeds of Plantago asiatica L. Kor J Pharmacogn. 2007;38:376-81.

26. Shin JS. Saponin composition of Liriope platyphlla and Ophiopogon japonicus. Kor J Srop Sci. 2002;47:236-9.

27. Mocan A, Vlase L, Vodnar DC, Bischin C, Hanganu D, Gheldiu AM, et al. Polyphenolic content, antioxidant and antimicrobial activities of Lycium barbarum L. and Lycium chinense Mill. leaves. Molecules. 2014;19(7):10056-73.

28. Zhang Q, Ye M. Chemical analysis of the Chinese herbal medicine Gan-Cao (licorice). J Chromatogr A. 2009;1216(11):1954-69.

29. Laskin DL, Pendino KJ. Macrophages and inflammatory mediators in tissue injury. Annu Rev Pharmacol Toxicol. 1995;35:655-77.

30. Sharma JN, Al-Omran A, Parvathy SS. Role of nitric oxide in inflammatory diseases. Inflammopharmacology. 2007;15(6):252-9.

31. Turini ME, DuBois RN. Cyclooxygenase-2: a therapeutic target. Annu Rev Med. 2002;53:35-57.

32. Rocca B, FitzGerald GA. Cyclooxygenases and prostaglandins: shaping up the immune response. Int Immunopharmacol. 2002;2(5):603-30.

33. Singh VP, Patil CS, Jain NK, Kulkarni SK. Aggravation of inflammatory bowel disease by cyclooxygenase-2 inhibitors in rats. Pharmacology. 2004;72(2):77-84.

34. Ci X, Ren R, Xu K, Li H, Yu Q, Song Y, et al. Schisantherin A exhibits antiinflammatory properties by down-regulating NF-kappaB and MAPK signaling pathways in lipopolysaccharide-treated RAW 264.7 cells. Inflammation. 2010;33(2):126-36.

35. Jahnz-Rozyk K, Targowski T, Paluchowska E, Owczarek W, Kucharczyk A Serum thymus and activation-regulated chemokine, macrophage-derived chemokine and eotaxin as markers of severity of atopic dermatitis. Allergy. 2005;60(5):685-8.

36. Shimada Y, Takehara K, Sato S. Both Th2 and Th1 chemokines (TARC/CCL17, MDC/CCL22, and Mig/CXCL9) are elevated in sera from patients with atopic dermatitis. J Dermatol Sci. 2004;34(3):201-8.

37. Ju SM, Song HY, Lee SJ, Seo WY, Sin DH, Goh AR, et al. Suppression of thymus- and activation-regulated chemokine (TARC/CCL17) production by 1,2,3,4,6-penta-O-galloyl-beta-D-glucose via blockade of NF-kappaB and STAT1 activation in the HaCaT cells. Biochem Biophys Res Commun. 2009;387(1):115-20.

\section{Submit your next manuscript to BioMed Central and take full advantage of:}

- Convenient online submission

- Thorough peer review

- No space constraints or color figure charges

- Immediate publication on acceptance

- Inclusion in PubMed, CAS, Scopus and Google Scholar

- Research which is freely available for redistribution

Submit your manuscript at www.biomedcentral.com/submit 